\title{
Populaçōes de térmitas (Insecta: Isoptera) em quatro habitats no baixo rio Negro
}

\author{
Alan E. Mill (")
}

\section{Resumo}

Foram investigadas as faunas de cupins em quatro locais no baixo rio Negro, perto de Manaus. Três locais foram em regiōes elevadas, que não são inundadas, durante a enchente do rio: (1) floresta primária de terra firme, (2) floresta primária numa ilha no arquipélago de Anavilhanas e (3) capoeira de terra firme. O quarto foi a floresta periodicamente inundada (igapó) na beira da ilha estudada. Floresta primária de terra firme tem o maior número de espécies de cupins ( 43 espécies). Em capoeira, a população é menor (34 espécies), por causa dos efeitos de desmatamento. A floresta primária numa ilha no arquipélago tem um total ainda menor (19 espécies), provavelmente em virtude do seu isolamento. A fauna menor está no igapó (12 espécies), face às periódicas inundações que restringem a colonizaçăo dos cupins. A densidade de cupins foi muito maior na ilha do que na terra firme mais por causa da relação de competição por alimentação com outras espécies de cupins do que por causa da relação de predaçăo. Os cupins melhor adaptados à vida em capoeira, nas ilhas e até nos igapós, são espécies que podem tornar-se pragas na silvicultura, isto é, espécies de Coptotermes e de Nasutitermes.

\section{INTRODUÇÃo}

Os cupins, ou térmitas, formam a pequena e primitiva ordem Isoptera, no complexo orthopteroide. Todos os representantes da ordem são sociais, mas a origem da sociabilidade nos cupins é desconhecida. $O$ estudo sobre estes insetos começou há dois séculos com as atividades de exploradores e naturalistas amadores, como os ingleses Henry Smeathman na África e Henry Walter Bates no Brasil. Infelizmente, após este período de exploração, pouco foi feito para conhecer melhor a biologia e ecologia dos térmitas neotropicais, em comparação com os numerosos estudos sobre as faunas de outras regiões tropicais.

Os primeiros estudos sérios sobre a fauna Drasileira de cupins foram feitos por Rena- to L. Araujo, que dedicara a estes sua vida clesde os anos 1940, até o seu infeliz falecimento em 1978. Concentrou sua atenção na taxonomia, principalmente dos térmitas dos Estados de São Paulo e Minas Gerais. Mathews (1977) no Estado de Mato Grosso, Sylvester-Bradley et al. (1978) e Bandeira (1979a), na Amazônia Central, iniciaram o estudo ecológico de cupins no Brasil. Atualmente, a biologia e a ecologia dos térmitas neotropicais estão atraindo a atenção de muitos pesquisadores.

Existem no Brasil cerca de 200 espécies descritas de cupins, mas pouco se sabe sobre sua biologia e ecologia. A riqueza de espécies na floresta hileiana, ou amazônica, é bem evidente para árvores, vertebrados e alguns insetos comuns. Richards (1973) indica que a floresta amazônica contêm mais espécies de plantas e animais do que qualquer outro ecossistema do mundo. Cupins formam uma grande proporção da biomassa de invertebrados na Amazônia Central (Fittkau \& Klinge, 1973), mas sobre suas populaçōes na região amazônica pouco é sabido. O único trabalho publicado nesta área é um estudo da fauna de cupins em floresta primária no parque nacional do Tapajós (Bandeira, 1979b).

No presente estudo, foram examinadas as populações e ecologia geral de cupins em quatro locais diferentes. Os dados ecológicos estão apresentados e discutidas as diferenças entre os locais e entre as quatro populações de cupins.

\section{ÁREAS DE ESTUdo}

Esta pesquisa foi realizada principalmente na estação ecológica Anavilhanas, da Secretaria Especial do Meio Ambiente (SEMA) do

(*) - Universidade de Brasília, Distrito Federal. 
Ministério do Interior. A estação está localizada aproximadamente $2^{\circ} 00^{\prime}$ até $3^{\circ} 02^{\prime} \mathrm{S}$ e $60^{\circ} 27^{\prime}$ até $61^{\circ} 07^{\prime} \mathrm{W}$. Consiste do arquipélago de Anavilhanas e de uma região de terra firme na margem esquerda do rio Negro. Na estação ecológica, a diferença entre o nível da água do rio na enchente e na vazante atinge até $14 \mathrm{~m}$. Durante a enchente, extensas regiões de floresta das ilhas do arquipélago e das margens do rio são inundadas, formando igapós, ou regiões de "floresta inundável". As adaptações dos invertebrados e a importância dos artrópodos terrestres no ecossistema "floresta inundável" foram estudadas por Adis (1977, 1979). Além de registrar a presença de 12 espécies de cupins arbóreos nos igapós do arquipélago (cf. Tabela 1), o interesse neste trabalho foi centralizado nas regiōes elevadas de floresta que não são inundadas durante a enchente do rio.

Três locais (um dos quais fora da estação ecológica) foram escolhidos para realizar este trabalho. O primeiro foi a floresta primária na terra firme, na margem esquerda do rio Negro. O segundo foi em lugar elevado de floresta primária numa ilha no meio do arquipélago que não é inundada durante a enchente do rio. O terceiro local ficou fora da estação ecológica e foi numa floresta secundátia de terra firme à margem esquerda do rio. A área foi desmatada nos anos 1970-1971 para ag̀ricultura de subsistência, a qual foi recolonizada rapidamente por plantas invasoras; e atualmente está coberta por capoeira ou floresta secundária.

\section{MATERIAIS E MÉTODOS}

Foi examinada a presença de cupins numa área de um ha de cada local estudado. Os cupins foram coletados com pincel e conservados em álcool a $75 \%$. A localização do ninho de cada cupim foi registrada juntamente com a fonte de alimentação e área de forrageamento. A abundância de espécies de cupins que fazem ninho no chão e nas árvores de cada área foi registrada.

As espécies foram identificadas comparando-as com os cupins das coleções do $\mathrm{Mu}$ seu Emílio Goeldi (Belém do Pará), da Univer- sidade de Brasília (Distrito Federal) e do Museu de Zoologia da Universidade de São Paulo (S.P.).

\section{Resultados}

Uma súmula da distribuição global das espécies de cupins coletados junto com seus dados ecológicos estão apresentados em Tabela 1 . O número máximo de espécies (43 espécies) foi encontrado na floresta primária na beira do rio. Nos outros locais foram encontradas apenas parte deste total de 43 espécies, isto é, não foram registradas espécies que não tivessem ocorrência na floresta primária. Estão apresentados, na Tabela 2, as abundâncias relativas e dados sobre forrageamento para as seis espécies estudadas em mais detalhe. Em Tabsla 3 está apresentada a distribuição de espécies entre os tiês pussíveis locais de ninhos (arbóreo, epígeo e hipógeo; vide discussão) de cada populaçăo estudada.

Para comparar as populações nos quatro locais, o "índice de similaridade" (i) de Mountford (in Southwood, 1976) foi utilizado com os dados da Tabela 3. A fórmula básica é:

$$
I=\frac{2 j}{2 a b-(a+b) j}
$$

onde $a=$ número de espécies om habitat $A$; $\mathrm{b}=$ número de espécies em habitat $\mathrm{B} ; \mathrm{e}$ $\mathrm{j}=$ número de espécies com' is nos dois habitats. Este índice versátil permite a derivação de I para uma série de $\mathrm{m}$ locais comparando com outra série de $\mathrm{n}$ locais, usando a fórmula geral:

$$
\frac{1}{m n} \sum_{i=1}^{m} \sum_{j=1}^{n} I\left(A_{i} B_{j}\right) \quad \ldots 2
$$

Considerando os quatro habitats estudados em série "A, B, C, D", as duas fórmulas forem utilizadas (cf. Southwood, 1976; ou Mountfo d, 1962, para detalhes) para determinar o valor de I entre os membros da série (Tabela 4). Estes valores foram utilizados para construir a classificação das populações de cupins apresentada na Figura 1. 


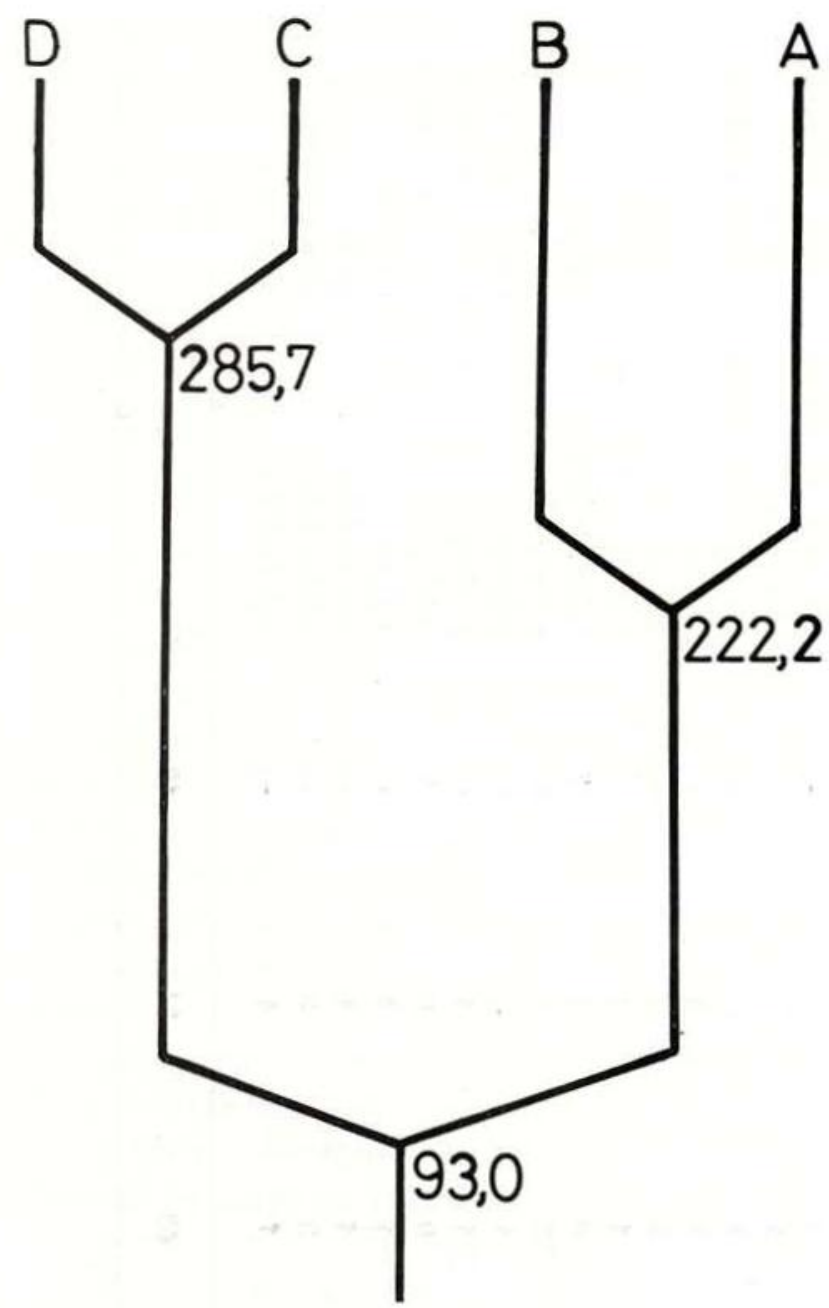

Fig. 1 - Classificação das populaçōes de cupins em quatro locais no baixo rio Negro, baseada nos seus "índices de similaridade" (I). As letras em parenteses foram usadas nas fórmulas para representar as populações dos quatro locais (cf. Tabela 4).

\section{Discussões}

Estudos realizados em outras regiöes tropicais mostraram que a distribuição de térmitas em qualquer ecossistema sempre é tal que os termiteiros e as estruturas de forrageamento das espécies presentes podem ser arbóreos (dentro ou fixados em árvores ou arbustos), epígeos ou hipógeos. Pode ver-se, nos dados na Tabela 3 , que das 43 espécies de cupins coletados na floresta primária de terra firme, 25 espécies ( $58 \%$ da população) são arbóneas, 12 espécies $(28 \%)$ constroem cupinzeiros epígeos e 6 espécies (14\%) são hipógeas.
$\mathrm{Na}$ área de capoeira, foram encontradas apenas 34 espécies de cupins. A diferença na distribuição destas espécies (20 espécies arbóreas ( $59 \%$ da população), 9 epígeas $(26 \%)$ e 5 hipógeas $(15 \%)$ ) e devida à diferença entre os habitats, já que a distribuição de espécies de cupins entre os três níveis está relacionada com fatores ecológicos. $\mathrm{Na}$ área de capoeira, a distribuição é diferente e a população é menor, em relação à floresta primária, provavelmente em virtude dos efeitos de desmatamento (Bandeira, 1979a). O efeito mais óbvio de desmatamento é a redução nos números de espécies, as quais constroem nihos arbóreos ou se alimentam de madeira viva (de 25 na floresta primária até 20 na capoeira). Note-se que percentagem (Tabela 3) de espécies arbóreas não muda significantemente. As espécies arbóreas mantêm constante sua proporção nas duas populações. A remoção das árvores deixa a área desmatada temporariamente inabitável para algumas destas espécies e seus nichos ecológicos são ocupados por outras espécies menos sensíveis. Estas são principalmente espécies que podem tornar-se pragas na silvicultura, como as espécies de Coptotermes e Nasutitermes.

Muitos cupins de floresta que vivem em cupinzeiros epígeos também não conseguem viver em áreas desmatadas (Sands, 1965; Wood, 1975; Bandeira, 1979a; e dados nas Tabelas 1 e 3 ). Não apenas muda o número de espécies presentes (de 12 na floresta primária até 9 na capoeira) mas também sua proporção nas populações (de $28 \%$ até $26 \%$ ). Porém a razão deste efeito é ainda desconhecida. Talvez a alteração dos elementos microclimáticos não permita a manutenção de colônias de cupins sensiveis. Não foram estudadas as diferenças microclimáticas entre a floresta primária e a floresta secundária (capoeira), mas a diferença na vegetação dos dois locais sugere que os dois habitats são diferentes. Wood (1975), examinando trabalhos feitos na África em áreas desmatadas e os efeitos sobre as populações de térmitas, afirma que tais áreas são habitats muito diferentes quando comparadas com a floresta primária. 
TABELA 1 - Distribuição das espécies de cupins coletados em quatro habitats no baixo rio Negro. Dados ecológicos estão apresentados para cada gênero. Dos cupins indicados com asterisco, uma só colônia foi encontrada nas áreas estudadas

Número de espécies encontradas em cada ambiente

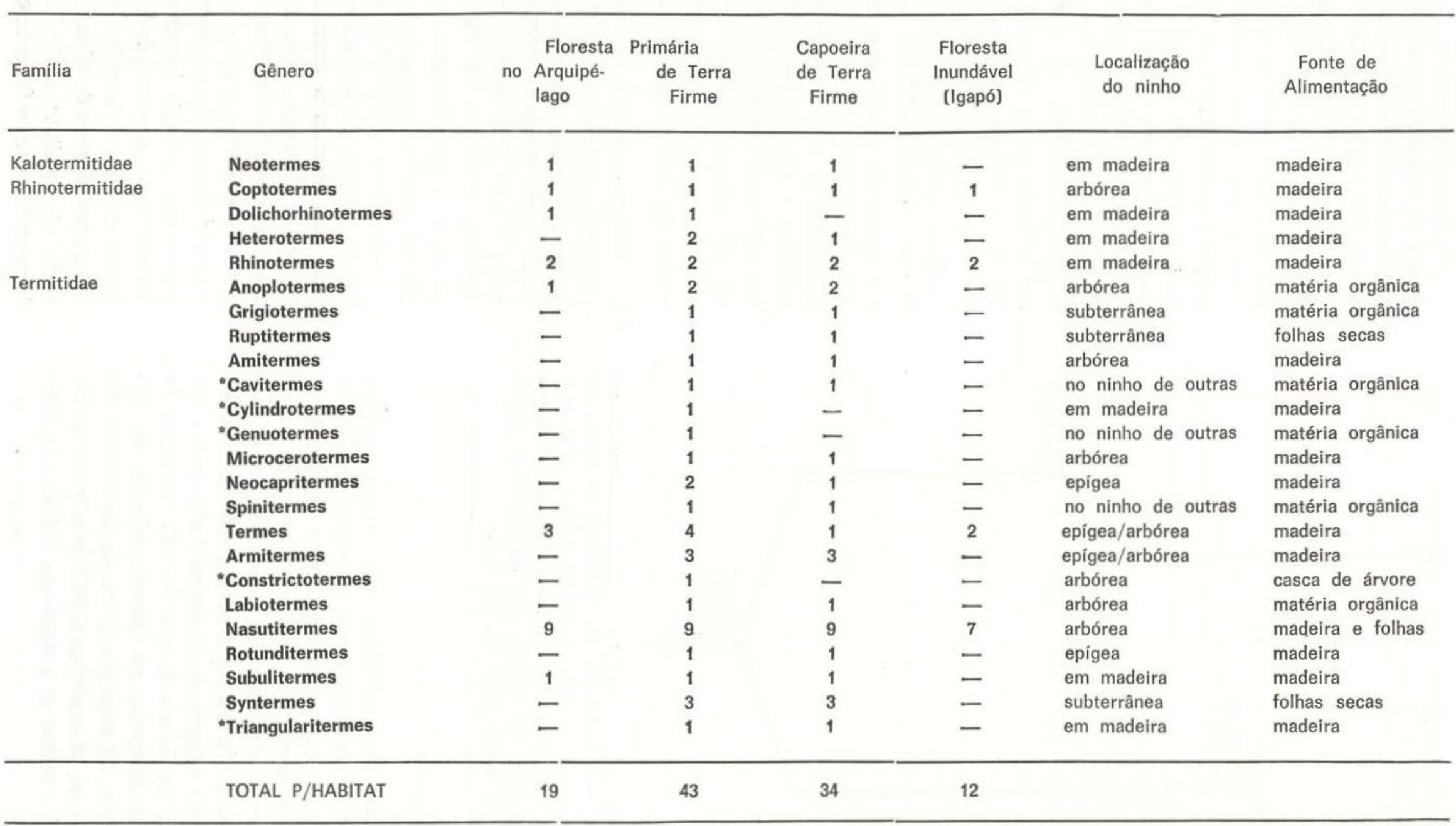


O pequeno incremento na proporção das espécies subterrâneas na capoeira é apenas aparente. É causado pela redução do número das espécies epígeas, como mostram os dados da Tabela 3.

Porém, a vegetação na floresta primária. na beira do rio e a vegetação da ilha estudada no arquipélago foram quase iguais. MacArthur \& Wilson (1967) afirmam que, numa região com habitat, vegetação e clima relativamente uniformes, existe uma relação óbvia entre o tamanho de áreas estudadas nesta região e o número de espécies nelas encontrado. Mas foi demonstrado neste estudo que uma área de um ha de floresta primária na terra firme contém 43 espécies de cupins e que numa área de um ha de floresta primária na ilha, apenas 19 espécies (Tabela 1). A área de terra firme estudada na floresta primária tem pequeno número de colônias de cupins (às vezes, uma só colônia, indicada na Tabela $1 \mathrm{com}$ asterístico) que pertencem às espécies que competem pelos mesmos recursos desta área. Esta grande diversidade e pequena abundância é uma característica da fauna e flora da floresta amazônica (Richards, 1973). Na terra firme tem uma maior representação de espécies invasoras ou transientes (MacArthur \& Wilson, 1967) do que as ilhas do arquipélago. As ilhas são áreas mais isoladas, nas quais as espécies transientes não podem atingir. Neste caso, a largura do rio e da floresta inundável na beira, junto com os efeitos ecológi$\cos$ das enchentes formam uma barreira ecológica que impede estas espécies de atingirem as ilhas.

A dispersão de cupins é efetuada pelo vôo nupcial anual dos reprodutores alados, geralmente no início da estação das enchentes do rio, o verão chuvoso. Krishna (1970) informa que os reprodutores são voadores fracos e débeis e não podem atravessar grandes extenções de água, como neste rio. Eles cobrem um máximo de 400-600 m em vôo (Mill, não pub.), mas a distância mínima entre a beira e as ilhas mais próximas excede $750 \mathrm{~m}$; a distância média é de $1400 \pm 300 \mathrm{~m}$. Nas ilhas, as áreas elevadas são poucas e afastadas da beira do rio; os cupins conseguem atingir estas áreas somente por meio de regiōes inundáveis de floresta. A enchente do rio que inunda os igapós não permite os cupins estabəlecerem ninhos subterrâneos ou epígeos na floresta inundável. Portanto as espécies que não são arbóreas não podem colonizar estes locais. As espécies encontradas nos igapós têm que estar adaptadas às condiçōes da vida deste local, por exemplo, às inundações do chão da floresta pelas águas do rio durante uma parte do ano. Espécies hipógeas, ou epígeas ou as

TABELA 2 - Densidade relativa e extenções médias das galerias de forrageamento de seis espécies de cupins co. muns nas áreas estudadas. Nomes especificos abreviados: acan. $=\mathrm{N}$. acangussu; ephr. $=\mathrm{N}$. ephratae; guay. $=\mathrm{N}$. guayanae; macr. $=\mathrm{N}$. macrocephalus; nigr. $=\mathrm{N}$. nigriceps

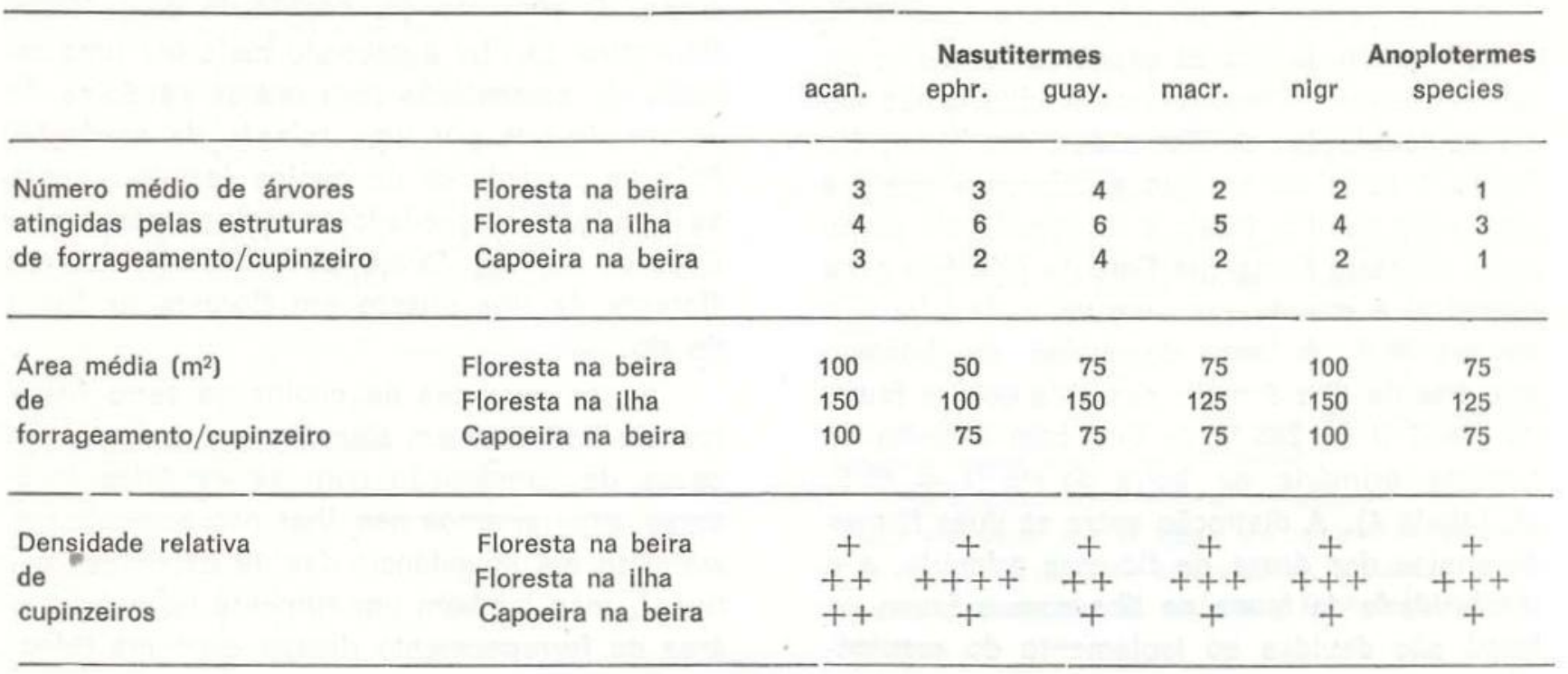

Populações... 
TABELA 3 - Localizaçăo de ninho para os térmitas nos quatro habitats estudados no baixo rio Negro

\begin{tabular}{|c|c|c|c|c|}
\hline \multirow{2}{*}{ Habitat } & \multirow{2}{*}{$\begin{array}{l}\text { Total de } \\
\text { espécies }\end{array}$} & \multicolumn{3}{|c|}{$\begin{array}{l}\text { Número de espécies (com percentagem do total) } \\
\text { construindo ninhos: }\end{array}$} \\
\hline & & Arbóreos & Epígeos & Subterrâneos \\
\hline Floresta primária no arquipélago & 19 & $19(100 \%)$ & $\ldots$ & $\ldots$ \\
\hline Floresta primária de terra firme & 43 & $25(58 \%)$ & $12(28 \%)$ & $6(14 \%)$ \\
\hline Capoeira de terra firme & 34 & $20(59 \%)$ & $9(26 \%)$ & $5(15 \%)$ \\
\hline Floresta inundável (igapó) & 12 & $12(100 \%)$ & $\ldots$ & ... \\
\hline
\end{tabular}

que vivem em madeira ou troncos caídos no chão na beira do rio, como Heterotermes tenuis, Rotunditermes bragantinus e Syntermes molestus, não foram encontradas nos igapós. Todas as espécies colonizadores das ilhas constroem ninhos arbóreos ou em madeira morta mas ainda em pé. Assim, somente cupins que constroem ninhos arbóreos podem colonizar as áreas elevadas nas ilhas. Dados, nas Tabelas 1 e 3 , mostram que todas as espécies nos igapós e na ilha estudada são arbóreas. Isto forma um grande contraste com as faunas de cupins de terra firme, onde apenas $58-59 \%$ das espécies são arbóreas (Tabela 3).

A diversidade de habitat e diferenças em vegetação e microclima entre floresta primária e capoeira, na beira do rio, são os principais responsáveis pelas diferenças nas populações de térmitas nas áreas estudadas. Nas áreas elevadas de floresta primária no arquipélago de Anavilhanas e na beira do rio, o habitat é praticamente uniforme e invariável. $\mathrm{O}$ isolamento da ilha às espécies invasoras ou transientes é responsável pelas diferenças entre as populações da ilha e de terra firme. $\mathrm{Na}$ figura 1 pode ver-se que a diferença entre a população da ilha (mais a do igapó) e a população na terra firme (na floresta primária e na capoeira) é grande, com um valor de I iguai a apenas 93,0. A fauna de cupins na floresta primária da ilha é mais parecida com a fauna do igapó $(I=285,7)$ do que com a fauna da floresta primária na beira do rio $(I=833$; cf. Tabela 4). A distinção entre as duas faunas de cupins das áreas de floresta primária, e a similaridade da fauna na ilha com a fauna no igapó são devidas ao isolamento do arquipé- lago e aos efeitos ecológicos das enchentes do rio.

Entre as faunas na capoeira e na floresta primária de terra firme, I \% 222,2. Isto é menor do que o valor entre as faunas do igapó e da ilha $(I=285,7)$, indicando que os efeitos de desmatamento sobre as populações de cupins são mais sérios do que as diferenças naturais entre habitats na floresta.

Uma comparação entre a fauna de cupins encontrados num hectare de floresta do arquipélago e a fauna de um hectare de floresta na beira do rio permite dar-nos uma descrição detalhada das espécies livres de competição. $\mathrm{Na}$ área estudada do arquipélago, foram registradas somente 19 das espécies encontradas na floresta de terra firme. Embora este número corresponda apenas à metade do número de espécies de terra firme, encontrou-se uma densidade muito superior de termiteiros na ilha do que na terra firme. Cada termiteiro representa uma colônia formado por dois reprodutores. O aumento em densidade de colônias de cupins na ilha é causado mais por uma relação de competição com outras espécies de cupins do que por uma relação de predação. Pois os predadores de cupins (especialmente as formigas, os predadores mais ativos e efetivos de cupins) foram observados tanto em floresta da ilha quanto em floresta na beira do rio.

Se as espécies de cupins na terra firme fossem limitadas em abundância e habitat, por causa de competição com as espécies invasoras, esperariamos nas ilhas não somente um aumento em abundância das 19 espécies "nativas", mas também um aumento no habitat e área de forrageamento destas espécies (Mac 
Arthur, 1972). As distâncias médias das galerias de forrageamento das cinco espécies do gênero Nasutitermes mais comuns nas áreas estudadas e da única espécie de Anoplotermes comum nas três áreas estão apresentadas na Tabela 2. As espécies da ilha forrageiam em uma área bem maior do que as de terra firme (Tabela 2), mas não mudam a fonte de alimentação (Tabela 1). Na floresta de terra firme, a espécie de Anoplotermes tem que competir com Amitermes excellens e Subulitermes spp. para sua alimentação. Esta competição reduz tanto a extensão de forrageamento da espécie quanto também a densidade de colônias. A mesma coisa acontece com as cinco espécies de Nasutitermes. Na floresta de terra firme, elas competem pelos recursos com espécies dos gêneros Armitermes, Cylindrotermes, Heterotermes, Labiotermes, Microcerotermes, Neocapritermes, Rotunditermes e Ruptitermes. Estes são gêneros que não conseguem invadir e colonizar as ilhas.

As espécies de Nasutitermes e Anoplotermes da ilha expandem seu habitat e invadem as regiões de bambu (onde cairam árvores grandes e velhas, deixando clareiras para o bambu invadir) e vegetação densa na beira das

TABELA 4 - indices de similaridade calculados para as faunas de cupins nos quatro habitats estudados, utilizando as fórmulas de Mountford (in Southwood, 1976)

Habitats: $A=$ Floresta primária de terra firme

$B=$ Capoeira de terra firme

C = Floresta primária no arquipélago

$\mathrm{D}=$ Floresta inundável (igapó)

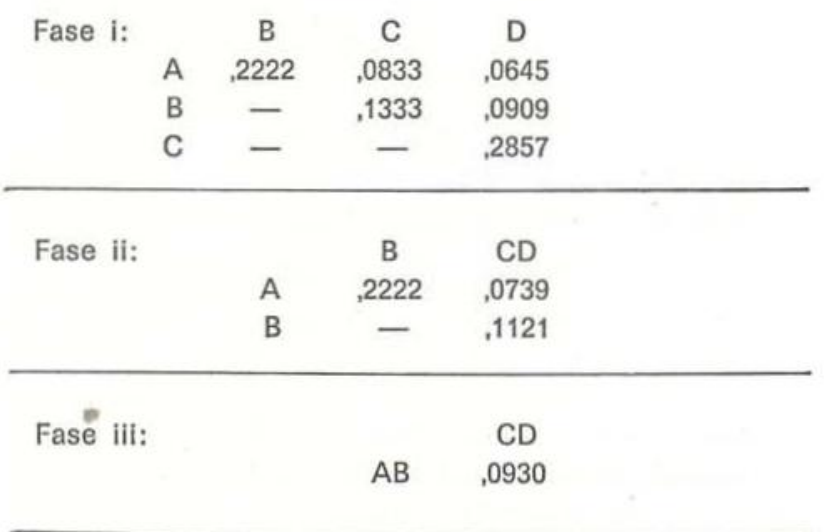

ilhas. Na floresta de terra firme, elas estäo mais restritas à própria floresta. Outras espé. cies ocorrem no bambu e na vegstação densa na beira das águas, como outras espécies de Nasutitermes, Ruptitermes arboreus, etc.

Os efeitos de desmatamento e isolamento são fatores importantes na ecologia dos cupins de florestas neotropicais. A maioria de térmitas da floresta primária é muito sensivel a tais efeitos e não consegue sobreviver à mudança no habitat. Os poucos cupins que podem adaptar-se a estes efeitos são espécies que podem tornar-se com facilidade pragas na silvicultura.

\section{Agradecimentos}

Ao Science and Engineering Research Council da Grã-Bretanha e Shell Biosciences Ltd. pela concessão da bolsa de estudo "CASE"; Secretaria Especial do Meio Ambiente, Ministério do Interior, pelo apoio para realizar este trabalho; e Kiniti Kitayama, pela ajuda na preparação deste artigo.

\section{SUMMARY}

A comparison was made of termite populations in four different forest habitats along the lower Rio Negro, near Manaus. Three of the habitats were on floodfree elevations while the fourth was periodically inundated by the river's flood. Flood-free primary forest along the river bank had the highest number of species (43 spp.); flood-free secondary forest (capoeira) on the bank had a lower total ( $34 \mathrm{spp}$.) due to Man's interference with the environment. A much lesser species richness was found in flood-free primary forest on an island in the Anavilhanas archipelago (19 spp.) due to its ecological isolation from the river bank faunas. Periodically flooded forest (igapó) in the archipelago had the lowest total (12 spp.), being a habitat unsuitable for colonisation by most termites.

Less than half as many species occurred in primary forest on the island as were found in an equal area of primary forest on the bank. Due to release from foraging competition with other termites, the density of these 19 island species was far higher than that of those on the river bank and their habitats and foraging ranges were also increased.

The termites best adapted to secondary forest, to island existence and to igapó are species of potential pest status in forestry: Coptotermes testaceus and 9 species of Nasutitermes, especially $\mathbf{N}$. ephratae and $\mathbf{N}$. nigriceps. 


\section{REFERENCIAS BIBLIOGRAFICAS}

ADIS, J.

1977 - Programa mínimo para análises de ecossistemas: Antrópodos terrestres em florestas inundáveis da Amazônia Central. Acta Amazonica, 7 (2): 223-229.

1979 - Vergleichende Oekologische Studien an der Terrestrichen Arthropodenfauna Zentralamazonischer Ueberschwemmungswalder. Dissertação de PhD. Universidade de Ulm, Alemanha. 99pp.

BANDEIRA, A.G.

1979a- Ecologia de cupins (Insecta: Isoptera) da Amazônia Central: efeitos do desmatamento sobre as populaçōes. Acta Amazonica, 9 (3): $481-499$.

1979b - Notas sobre a fauna de cupins (Insecta: Isoptera) do Parque Nacional da Amazônia (Tapajós), Brasil. Bol. Mus. Paraense E. Goeldi; Zoologia, 96. 12pp.

FITTKAU, E.J. \& KLINGE, H.

1973 - On biomass and trophic structure of the Central Amazonian rain forest ecosystem. Biotropica, 5 (1): 2-14.

KRISHNA, K.

1970 - Taxonomy, Phylogeny and Distribution of Termites. In Krishna, K., \& Weesner, F.M., (eds.), Biology of Termites II. London. Academic Press, p. 127-152.

MacARTHUR, R.H.

1972 - Geographical Ecology. Harper \& Row, New York. XVIII + 269pp.

MacARTHUR, R.H. \& WILSON, E.O.

1967 - The theory of island biogeography New Jersey. Princeton Univ. Press, 203 pp.
MATHEWS, A.G.A.

1977 - Studies on termites from the Mato Grosso State, Brazil. Rio de Janeiro. Acad. Bras. de Ciências. 267pp.

MOUNTFORD, M.D.

1962 - An index of similarity and its application to classificatory problems. In Murphy, P.W. (ed.), Progress in Soil Zoology, p. 43-50.

RICHARDS, P.W.

1973 - The tropical rain forest. Sci. Amer., 229: 58-67.

SANDS, W.A.

1965 - Termite distribution in man-modified habitats in West Africa, with special reference to species segregation in the genus Trinervitermes (Isoptera: Termitidae: Nasutitermitinae). J. Animal Ecol., 34: 557.571.

SOUTHWOOD, T.R.E.

1976 - Ecological Methods with particular reference to insect populations; London. Chapman \& Hall, 548pp.

SYLVESTER-BRADLEY, R.; BANDEIRA, A.G. \& de OLIVEIRA, L.A.

1978 - Fixação de nitrogênio (reduçăo de acetileno) em cupins (Insecta: Isoptera) da Amazônia Central. Acta Amazonica, 8 (4): 621627.

WOOD, T.G.

1975 - The effects of clearing and grazing on the termite fauna (Isoptera) of tropical savannas and woodlands. Progress in Soil Zoolo. gy (Proc. 5th Internat. Coll. Soil Zool.), p. 409-418.

(Aceito para publicação em $27 / 11 / 81$ ) 